\title{
Studies on Application of a Lead Acetate Solution as Filter to the Photochemical Reaction of Ergosterol to Improve the Yield of Vitamin D
}

\author{
Zhi-Ren LU, Ya-Fang PANG, Quan-Rong SHEN, \\ and Cheng-Fa ZHENG \\ Department of Nuclear Science, Fudan University, \\ Shanghai, China
}

(Received August 25, 1987)

\begin{abstract}
Summary Since a lead acetate solution can remove most of the ultraviolet (UV) light in the range below $275 \mathrm{~nm}$ which usually gives undesirable by-products in the photochemical conversion of ergosterol to vitamin $\mathrm{D}$, it is useful as a filter solution for the reaction to obtain higher yield of vitamin D. When a 5\% lead acetate solution was used as the filter, the yield of vitamin D was $20-25 \%$ higher than that without using filter solution.
\end{abstract}

Key Words filter solution, lead acetate, vitamin D, ergosterol, high pressure mercury lamp, ultraviolet light, photoisomerization, tachysterol, lumisterol, previtamin D

In the photochemical reaction of an ergosterol solution in ethanol, the yield of main photoisomerization products, i.e., previtamin D (hence, vitamin D), tachysterol, and lumisterol, are closely related with the wavelength of irradiating light. It has been shown that the UV light in the ranges of shorter and longer wavelengths predominantly gives tachysterol and lumisterol, respectively $(1,2)$. Abillion and Mermet-Bouvier (3) reported from theoretical calculation that a maximum yield of previtamin D occurred by the irradiation at $295 \mathrm{~nm}$, which was experimentally proved by Kobayashi and Yasumura (4) at nearly the same period. Evley and Williams (5) pointed out that tachysterol is a major photoproduct in the "quasi" photostationary state, and therefore the yield of previtamin $\mathrm{D}$ (hence, vitamin $\mathrm{D}$ ) is limited by the photochemical formation of tachysterol. Thus, one of the methods for improving the yield of vitamin D is to remove the UV light in the range below $275 \mathrm{~nm}$.

High pressure mercury lamps are still being applied to industrial production of vitamin D. However, its emission spectrum is quite rich in the range below $275 \mathrm{~nm}$ which gives more photoisomerization by-products, especially tachysterol, while less 
previtamin D or vitamin D. In order to improve the emission spectrum of a high pressure mercury lamp, some methods using filter (glass filter and filter solutions) were reported $(6,7)$. Organic filter solutions, such as methylbenzene, dimethylbenzene, or carbon disulfide, are limited in their application because of their combustibility and light unstability. In contrast, inorganic salt filter solutions show a good prospect for the purpose because of their adequate light stability. Sato et al. (8) investigated in detail inorganic filter solutions including $\mathrm{CuSO}_{4}, \mathrm{NiSO}_{4}$, and a mixture of $\mathrm{CuSO}_{4}-\mathrm{NiSO}_{4}$-quinine hydrochloride in the photochemical formation of 1-hydroxyvitamin $\mathrm{D}_{3}$. Sperti et al. (9) reported the use of a lead acetate solution on the photochemical reaction of provitamin $\mathrm{D}$, but detailed data on the yields of photoisomerized compounds have not yet been shown.

In this paper, we have investigated the transmission of lead acetate filter solutions in UV region; the possibility of application to improving the potential yield of vitamin $\mathrm{D}$ in the photochemical reaction of ergosterol is discussed.

\section{EXPERIMENTAL}

1. Reagents. 1) Lead acetate (guaranteed reagent), Vitamin $\mathrm{D}_{2}$, and ergosterol, accorded with Chinese Pharmacopoeia.

2) Filter solution: The weighed $\mathrm{Pb}(\mathrm{AcO})_{2} \cdot 3 \mathrm{H}_{2} \mathrm{O}$ were dissolved in distilled water with 1-2 drops of glacial acetate acid to make $2.5,5.0,10.0 \%$ concentrations of net lead acetate solution. In order to completely dissolve lead acetate in distilled water, it is necessary to add only a small amount of glacial acetate acid. An excessive amount leads to change of the absorption spectra of lead acetate.

3) Ergosterol solution to be irradiated: The concentration of ergosterol solution in ethanol $(95 \%$ A.R.) is $1.0 \mathrm{mg} / \mathrm{ml}$.

4) Internal standard solution: $p$-Dimethylaminobenzaldehyde (A.R.) is dissolved in 1,2-dichloroethane to make a concentration of $5.0 \mathrm{mg} / \mathrm{ml}$.

5) Mobile phase: A mixture of petroleum ether (spectral pure) and isopropanol $(99.2: 0.8, \mathrm{v} / \mathrm{v})$ is used.

2. Equipment. 1) The visible-ultraviolet spectrophotometer $(751$ model, Shanghai First Analytical Instrument Factory) was used to determine UV spectrum of lead acetate with different concentrations.

2) Photochemical reaction apparatus: The exciting source for photochemical reaction of ergosterol was a high pressure mercury lamp $(1 \mathrm{~kW})$. The photochemical reaction vessel consisted of two quartz cells (see Fig. 1), one $(11 \times 15 \times 60 \mathrm{~mm})$ is the front of the vessel, another $(14 \times 15 \times 60 \mathrm{~mm})$ is the back. The reaction vessel which was fixed on the window of the shield of the lamp was $12 \mathrm{~cm}$ away from the high pressure mercury lamp (see Fig. 2).

3) The high performance liquid chromatography (HPLC) (KYS model, The Institute of Organic Chemistry, Academy of Sciences) equipped with a UV detector at $254 \mathrm{~nm}$ was used for determination of the ergosterol and vitamin D. The chromatographic column is a stainless-steel tube $(5 \mathrm{~mm}$ i.d. $\times 20 \mathrm{~cm})$ packed with 


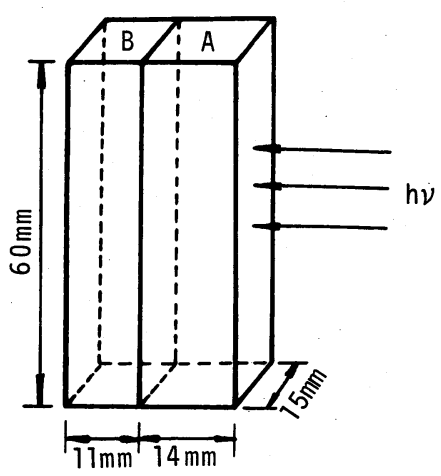

Fig. 1.

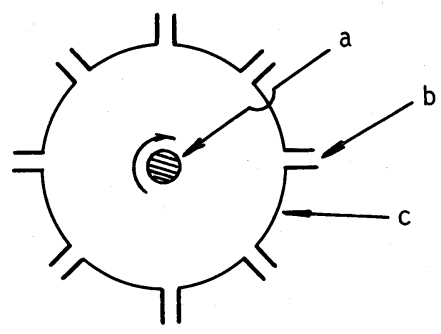

Fig. 2.

Fig. 1. The photochemical reaction vessel. A: The front cell for filter solution. B: The back cell for ergosterol solution.

Fig. 2. The sectional view of the photochemical reaction apparatus. a, the revolving lamp; $b$, the window; $c$, the shield of the lamp.

YWG silica gel $(\phi 5 \mu \mathrm{m})$.

3. UV-irradiation of ergosterol solution. A $7.5 \mathrm{ml}$ volume of the ergosterol solution in ethanol and $6 \mathrm{ml}$ of lead acetate solution were taken into cells, respectively. Irradiation of the solutions was started after the lamp was working for $20 \mathrm{~min}$. In order to keep irradiating solution below $40^{\circ} \mathrm{C}$, the reaction vessel was cooled by ice.

4. Determination of ergosterol and vitamin $D_{2}$ in irradiating ethanol solution by $H P L C$. 1) Preparation of standard solution: Accurately weighed $5.0 \mathrm{mg}$ of vitamin $\mathrm{D}_{2}$ or $25.0 \mathrm{mg}$ of ergosterol was dissolved into a $50 \mathrm{ml}$ brown volumetric flask with 1,2-dichloroethane, and $1.0 \mathrm{ml}$ internal standard solution $(5.0 \mathrm{mg} / \mathrm{ml})$ was added and diluted to the volume with 1,2-dichloroethane to make the concentrations of $0.5,0.5,0.1 \mathrm{mg} / \mathrm{ml}$ for internal standard, ergosterol, and vitamin $\mathrm{D}_{2}$, respectively.

2) Preparation of sample: $5.0 \mathrm{ml}$ of the irradiated ergosterol solution was poured into a $10 \mathrm{ml}$ round-bottom flask. The solvent (ethanol) was evaporated under reduced pressure at $\mathrm{O}_{2}$-free $\mathrm{N}_{2}$ and the resulting residue was dissolved by 6-7 $\mathrm{ml}$ of 1,2-dichloroethane. Then, the solution was refluxed at $83.5^{\circ} \mathrm{C}$ for over $1.5 \mathrm{~h}$ at $\mathrm{O}_{2}$-free $\mathrm{N}_{2}$ in order to reach an equilibrium of thermal isomerization between vitamin $D_{2}$ and previtamin $D_{2}$. The resulting solution was quantitatively transferred into a $10 \mathrm{ml}$ brown volumetric flask and $1.0 \mathrm{ml}$ internal standard solution was added, and was diluted to the volume with 1,2-dichloroethane.

3) HPLC: $4 \mu$ l of the sample solution and the standard solution obtained above were respectively injected into the chromatographic column by using a $10.0 \mu \mathrm{l}$ microsyringe. The analytical conditions were as follows: room temperature, $20-25^{\circ} \mathrm{C}$; flow rate, about $1.4 \mathrm{ml} / \mathrm{min}$; pressure about $40 \mathrm{~kg} / \mathrm{cm}^{2}$.

The contents of the unconverted ergosterol and vitamin $D_{2}$ in the sample 
solution were calculated by the following equations:

$$
\begin{aligned}
C_{\mathrm{E}, \mathrm{A}} & =C_{\mathrm{E}, \mathrm{s}} \frac{H_{\mathrm{I}}}{H} \cdot \frac{h_{\mathrm{E}}}{h_{\mathrm{I}}} \\
C_{\mathrm{D}, \mathrm{A}} & =C_{\mathrm{D}, \mathrm{s}} \cdot \frac{H_{\mathrm{I}}}{H_{\mathrm{D}}} \cdot \frac{h_{\mathrm{D}}}{h_{\mathrm{I}}}-\frac{1}{f} \\
T & =\left(C_{\mathrm{E}, \mathrm{B}}-C_{\mathrm{E}, \mathrm{A}}\right) \cdot 100 \% \\
Y & =\left(C_{\mathrm{D}, \mathrm{A}} / C_{\mathrm{E}, \mathrm{B}}-C_{\mathrm{E}, \mathrm{A}}\right) \cdot 100 \%
\end{aligned}
$$

where, $H_{\mathrm{I}}, H_{\mathrm{E}}$, and $H_{\mathrm{D}}$ : the mean values of the peak height of internal standard, ergosterol, and vitamin $\mathrm{D}_{2}$ in the standard solutions for 4 determinations on chromatogram, respectively; $h_{\mathrm{I}}, h_{\mathrm{E}}$, and $h_{\mathrm{D}}$ : the mean values of the peak height of internal standard, ergosterol, and vitamin $D_{2}$ in the sample solution for 4 determinations on chromatogram, respectively; $C_{\mathrm{E}, \mathrm{s}}$ and $C_{\mathrm{D}, \mathrm{s}}$ : the concentrations $(\mathrm{mg} / \mathrm{ml})$ of ergosterol and vitamin $\mathrm{D}_{2}$ in the standard solutions, respectively; $C_{\mathrm{E}, \mathrm{B}}$, $C_{\mathrm{E}, \mathrm{A}}$, and $C_{\mathrm{D}, \mathrm{A}}$ : the concentrations of ergosterol and vitamin $\mathrm{D}_{2}$ in sample solutions before and after irradiating, respectively; $f$ : the correction factor calculating the potential yield of vitamin $\mathrm{D}_{2}$. According to our work and to the literature (6), the ratio of previtamin $\mathrm{D}_{2}$ to vitamin $\mathrm{D}_{2}$ is $1: 4$ at $83.5^{\circ} \mathrm{C}$, thus $f=0.8 ; T$ : the per cent of the converted ergosterol in the sample solution after UV irradiation; $Y$ : the potential yield of vitamin $D_{2}$ in the sample solution after UV irradiation.

\section{RESULTS AND DISCUSSION}

\section{1) UV absorption spectra of lead acetate solutions}

UV absorption spectra of lead acetate solutions at 2.5, 5.0, 10.0\% concentrations are shown in Fig. 3. The transmission for 5.0\% lead acetate solution was only $10.0 \%$ at $275 \mathrm{~nm}$, but it was almost $100 \%$ at $295 \mathrm{~nm}$. The transmission exceeded $100 \%$ at above the $300 \mathrm{~nm}$ region as shown in Fig. 3, because the UV absorption was estimated by using water as a reference. The results suggested that the $5.0 \%$ lead acetate solution was useful as a filter solution because it removed the light in the region below $275 \mathrm{~nm}$ from a high pressure mercury lamp. In addition, the transmission for $2.5 \%$ lead acetate solution was too large at $275 \mathrm{~nm}$, whereas that of $10.0 \%$ lead acetate solution was not sufficiently large at $295 \mathrm{~nm}$. Thus, $5.0 \%$ lead acetate solution was suitable for a filter in the photochemical reaction among the three concentrations. Moreover, the light stability of lead acetate solution was very good.

2) Effect of filter solution on the conversion of ergosterol and potential yield of vitamin $D_{2}$

The time courses of the conversion $(T)$ of ergosterol and the potential yield $(Y)$ of vitamin $\mathrm{D}_{2}$ during irradiation of an ergosterol solution $(1.0 \mathrm{mg} / \mathrm{ml})$ without or 


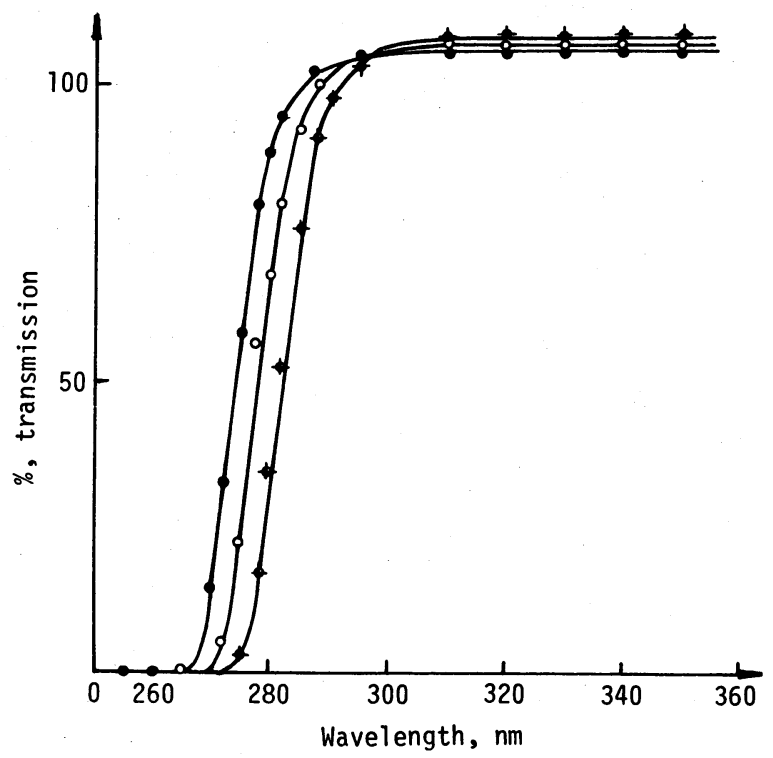

Fig. 3. Transmission of filter solution of lead acetate at differemt concentrations. $2.5 \%$ lead acetate solution; $\bigcirc, 5.0 \%$ lead acetate solution; $\phi, 10.0 \%$ lead acetate solution.

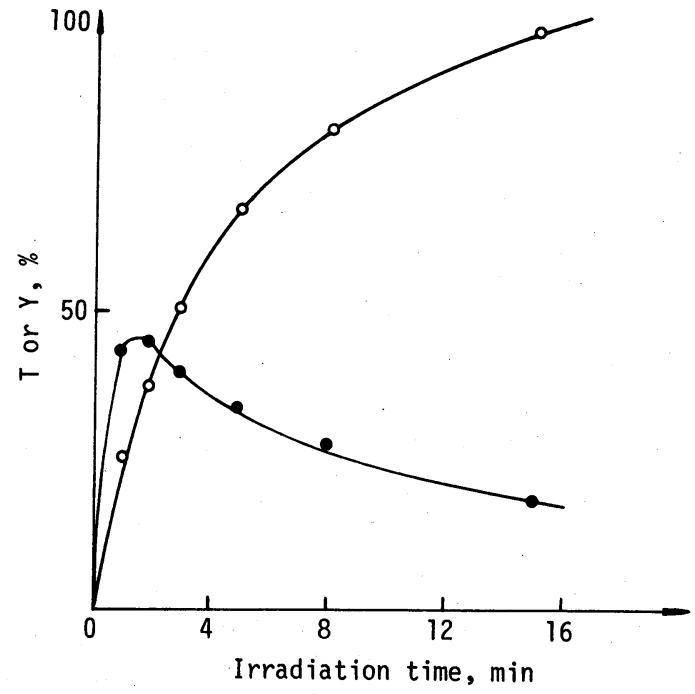

Fig. 4. Time course of the conversion of ergosterol and the potential yield of vitamin $\mathrm{D}_{2}$ in a solution of ergosterol $(1.0 \mathrm{mg} / \mathrm{ml})$ irradiated by a high pressure mercury lamp $(1 \mathrm{~kW})$ without a filter solution of lead acetate. $O$, conversion of ergosterol $(T)$; $\bullet$, potential yield of vitamin $\mathrm{D}_{2}(Y)$. 


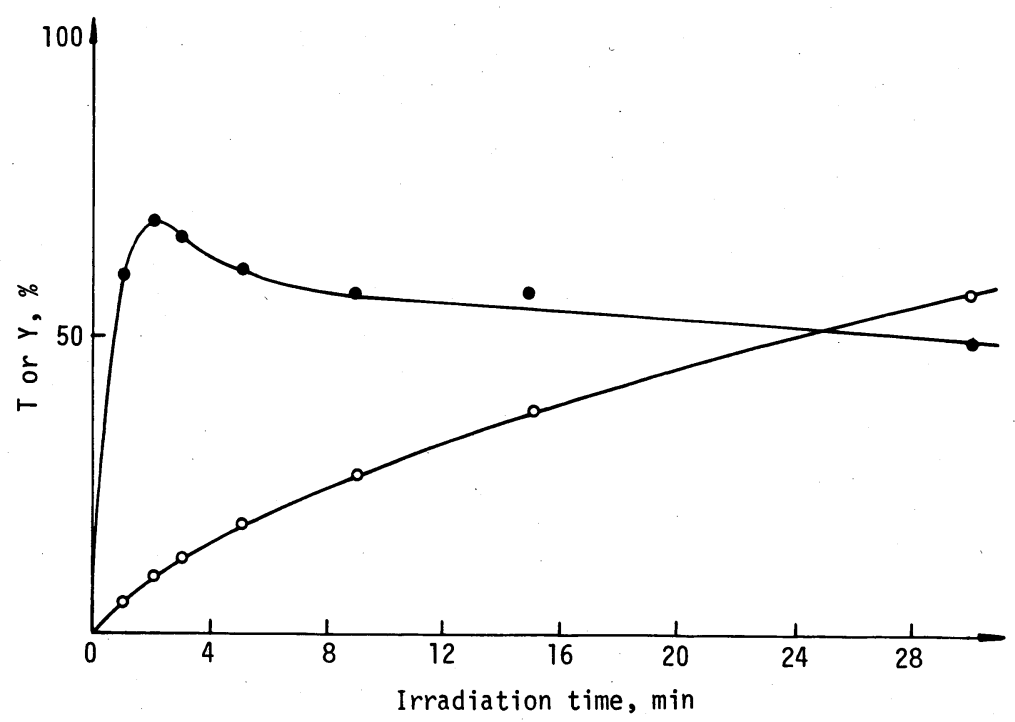

Fig. 5. Time course of the conversion of ergosterol and the potential yield of vitamin $\mathrm{D}_{2}$ in a solution of ergosterol $(1.0 \mathrm{mg} / \mathrm{ml})$ with $5.0 \%$ lead acetate solution as a filter. O, conversion of ergosterol $(T)$; $\bullet$, potential yield of vitamin $\mathrm{D}_{2}(Y)$.

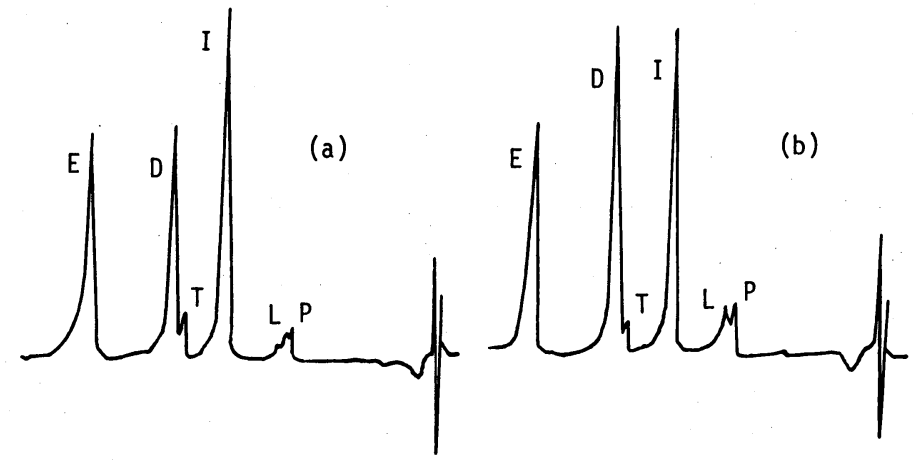

Fig. 6. The profile on the chromatograms of HPLC in a solution of ergosterol (1.0 $\mathrm{mg} / \mathrm{ml})$ irradiated by a high pressure mercury lamp $(1 \mathrm{~kW})$ without (a) or with a filter solution of $5.0 \%$ lead acetate (b).

with $5.0 \%$ lead acetate solution as a filter are shown in Figs. 4 and 5 respectively.

Significant difference was observed between the results of Figs. 4 and 5. The relationship between the potential yield of vitamin $D_{2}$ and the irradiating time showed that a maximum of the potential yield of vitamin $\mathrm{D}_{2}$ occurred at a certain irradiating duration. Comparing Fig. 4 with Fig. 5, however, it was easily found that the potential yield of vitamin $\mathrm{D}_{2}$ obtained with $5.0 \%$ lead acetate solution was obviously higher than the respective data without filter solution, because the 
Table 1. The comparison between the potential yields of vitamin $D_{2}$ with or without use of the filter solution of $5 \% \mathrm{~Pb}(\mathrm{AcO})_{2}$ in a solution of ergosterol $(1 \mathrm{mg} / \mathrm{ml})$ irradiated by a high pressure mercury lamp $(1 \mathrm{~kW})$.

\begin{tabular}{ccc}
\hline \multirow{2}{*}{$\begin{array}{c}\text { Conversion of } \\
\text { ergosterol } \\
(\%)\end{array}$} & Potential yield of $\mathrm{VD}_{2}(\%)$ \\
\cline { 2 - 3 } & with $5 \% \mathrm{~Pb}(\mathrm{AcO})_{2}$ filter solution & without filter solution \\
\hline 20.0 & 60.2 & 40.0 \\
30.0 & 57.2 & 44.4 \\
37.5 & 55.6 & 45.0 \\
50.0 & 52.2 & 41.0 \\
60.0 & 49.8 & 37.2 \\
\hline
\end{tabular}

formation of tachysterol was greatly limited (see Fig. 6). The increase of potential yield of vitamin $\mathrm{D}_{2}$ with the filter solution was $20-25 \%$ higher than that without a filter solution at $30-40 \%$ conversion of ergosterol (see Table 1). Furthermore, the potential yield of vitamin $\mathrm{D}_{2}$ obtained with the filter solution showed little decrease even when irradiation was prolonged after the maximum was achieved. This is also a superior merit of lead acetate filter solution. Although the light intensity of UV irradiation through a filter solution was considerably decreased, and the conversion of ergosterol was fairly reduced, the suitable conversion (e.g. $40 \%$ ) of ergosterol for preparation of vitamin $\mathrm{D}_{2}$ could be obtained by prolonging irradiating time. In addition, the method is quite simple, and no special equipment for the preparation of vitamin D was necessary. Of course, lead is more toxic than copper or nickel previously reported (8), but it is used in an entirely hermetic system and is thus also safe. Therefore, this method using the filter solution, lead acetate, will provide a practical use in industrial preparation of vitamin $\mathrm{D}$ by using a high pressure mercury lamp.

\section{REFERENCES}

1) Malatesta, V., Willis, C., and Hackett, P. A. (1981): Laser photochemical production of vitamin D. J. Am. Chem. Soc., 103, 6781-6783.

2) Dauben, W. G., and Phillips, R. B. (1982): Wavelength-controlled production of previtamin $\mathrm{D}_{3}$. J. Am. Chem. Soc., 104, 355-356.

3) Abillion, E., and Mermet-Bouvier, R. (1973): Effect of wavelength on production of previtamin $\mathrm{D}_{2}$. J. Pharm. Sci., 62, 1688-1689.

4) Kobayashi, T., and Yasumura, M. (1973): Study on the ultraviolet irradiation of provitamin $\mathrm{D}$ and its related compounds. III. Effect of wavelength on the formation of potential vitamin $\mathrm{D}_{2}$ in the irradiation of ergosterol by monochromatic ultraviolet rays. J. Nutr. Sci. Vitaminol., 19, 123-128.

5) Evley, S. C., and Williams, D. H. (1975): Photolytic production of vitamin D. Preparative value of a photosensitizer. J. Chem. Soc. Chem. Commun., 858.

Vol. 34, No. 3, 1988 
6) Jones, H., and Rasmusson, G. H. (1980): Recent advance in the biology and chemistry of vitamin D. Fortschr. Chem. Org. Naturs., 39, 63-121.

7) Yakhimovich, R. I., and Vendt, V. P. (1980): Photochemical isomerization of D provitamins in visual lamp irradiation. Khim-Farm. Zh., 14, 93-97.

8) Sato, T., Yamauchi, H., Ogata, Y., Kuni, T., Kagei, K., Katsui, G., Toyoshima, S., Yasumura, M., and Kobayashi, T. (1980): Effect of wavelength on the formation of $1 \alpha-$ hydroxyprevitamin $D_{3}$ in the ultraviolet irradiation of cholesta-5,7-diene-1 $\alpha, 3 \beta$-diol and use of a filter solution in the photochemical reaction in the synthesis of $1 \alpha$-hydroxy vitamin $\mathrm{D}_{3}$. J. Nutr. Sci. Vitaminol., 26, 545-546.

9) Sperti, G., Norris, R. T., Withdrow, R. B., and Schneider, H. (1934): U. S. Patent 1982029. 